\title{
MULTILAYERED EFFECTS OF NEW MEDIA AND SOCIAL NETWORKS ON CONTEMPORARY SPORTS
}

\author{
Uroš Mitrović, Danijela Bjelja
}

\begin{abstract}
Introduction
Over the past decade, new media based on digital online platforms, just like the omnipresent social networks, have experienced dramatic development and global expansion. You could say that they have taken the leading place in contemporary culture of communication among people, and have significantly changed the way we use them and experience them in everyday use.
\end{abstract}

Today's sports, as an open global activity, abundantly use the benefits of contemporary scientific knowledge and technology in the way of communication (Nešić, 2007).

Traditional, print, and electronic media, in particular new, online, and digital forms of mass communication and increasingly popular social networks have become an inevitable factor in the exchange of information, the transmission of messages, and overall in communication between athletes, clubs, and organizations dealing with sports activities and the most diverse targeted public.

\begin{abstract}
Aim and Objectives of the study
The subject of the paper is defined based on the theoretical setup of the research problem, and it relates to the impact of the contemporary sports industry on society through media. The aim is to determine and explain in what way the new media networks contribute to the increased interest in contemporary sports by considering multiple aspects.
\end{abstract}

\section{Methods}

The descriptive and theoretical-analytical methods were applied in this paper when analysing the relationship between the media and sports.

\section{Results and discussion \\ Media as a Catalyst for the Success and Popularity of the Sports Industry}

Relying on traditional media - press, radio and television - new digital online platforms allow users to follow sports events and competitions in real time, or simply whenever they want, online or using mobile applications, interactive social networks and/or specialized sports programs and channels, of which there is an increasing number on the market in line with the increased global demand.

Bearing in mind that traditional mass communication media has had a key role in the global promotion of sports, the new channels of communication and numerous social networks have additionally accelerated and improved the popularization of sports around the world.

Electronic media - television, radio, and digital computer technology - have completely changed the sports industry and its public relations. Before the development of radio broadcasts in 1920 and television broadcasts after 1930, the only people who witnessed a game were people who were at the stadiums (Masteralexis et al., 2005).

Today's most successful athletes have become global superstars and walking ads, whose personal wealth is measured in the hundreds of millions of Euros, thanks to the development of television and the expansion of communications technologies. Sport in itself has a remarkable promotional power, but thanks to the media that broadcast the information, first and foremost, the image and sound, it has reached unprecedented global popularity (Šurbatović, 2014).

Today, almost every athlete, team, league or sports association has a profile on social media, mainly on Facebook, Twitter or Instagram. "From the pros to the minors and from the high school athlete to the retired athlete", states the analysis of the influential US magazine Forbes, "social media has been a force in the sports industry landscape" (DiMoro, 2015). For this reason, the communication and behavior of an athlete or team on social media can directly affect the perception that fans have of this individual or sports organization. 
The Global Expansion of the Internet and New Social Media

In the late 1990 s and in early 2000 , the Internet grew from a specialized media mostly used by university staff and computer experts to the real mass media. In a study by the Pew Research Center (The Pew Internet and American Life Project, 1995, 1998, and 2002; http://www.people-press.org/) it was established that before 1995, only 14 percent of Americans were online. Just three years later this percentage rose to 36 and by 2002 the number of Americans using the Internet rose to 62 percent (Craig, 2010).

Some 15 years later, the data from a specialized Internet statistics website (http://www.internetworldstats.com) show that today around 4 billion people $(3,885,567,619)$ worldwide use this global network, and in North America alone this figure exceeds 320 million, with a percentage of use of over 88 percent. By far, Asia has the largest number of users with almost two billion people online.

As far as social networks are concerned, their development may have taken a shorter amount of time, but in the last decade alone the global expansion of the most diverse types of social networks has seen an incredible boom in the market.

Two marketing and consumer relations experts, Andreas M. Kaplan and Michael Haenlein, who in their research paper published in a scientific journal Business Horizons took to classification of social media (2010), state that there are six different types of social media:

1. Collaboration Projects - such as Wikipedia; 2. Blogs and Microblogs - Twitter; 3. Content Communities - YouTube; 4. Social Networking Sites - Facebook; 5. Virtual Game Worlds - World of Warcraft; 6. Virtual Social Worlds - Second Life (Kaplan, Haenlein, 2010).

A specialized portal Statista reports that Facebook, the most popular social network, already exceeded the number of 2 billion active monthly users in mid-2017. Active users are those who logged in on Facebook at least once in the last 30 days. The speed at which this social network has spread globally is best illustrated by the fact that Facebook (founded in 2004) needed less than eight years to reach a figure of one billion active monthly users, and less than five years to double the number of its users to the current 2.047 billion.

\section{Virtual Reality as a New Media Revolution}

In this modern, digitized world, communication and sports-media landscape are changing rapidly. Just as consumers continue to move away from traditional television, sports leagues, their broadcasters, and advertising partners must find creative ways to stay ahead of their consumers. The influential US web portal Business Insider correctly states that "the screen of choice isn't the only moving part in this sports-media revolution."

Viewers and those who follow sports are increasingly inclined to switch to specialized digital options to watch their favorite TV sports channels, either on demand or through streaming instead of classic television or cable subscriptions. The case of the famous US sports network ESPN, which had to find new solutions to deal with the decline in the traditional subscription to its program is a good example. "To combat this," according to a Business Insider analysis, "ESPN has focused in on digital, ramping up content on the WatchESPN app and ESPN3, ESPN's digital-only network" (Jason, 2017).

The development of technologies, such as virtual and augmented reality (VR/AR), and the advancement of digital platforms that allow for immersive viewing of 360-degree content, which is recorded with a multi-camera system, so the viewer can watch the video from all angles by shifting the image are quickly changing consumer expectations about how the content is displayed.

In line with market trends, but also out of the desire to survive in an increasingly competitive (and more expensive) market, many media networks have chosen to partner up with digital channels to broadcast the most famous sports events simultaneously and online. The UK's BT Sport network, for example, has found a partner in Google's YouTube, which allows viewers to watch the UEFA Champions League and the Europa League Final on YouTube for free. "Both soccer championships will be available both in the $4 \mathrm{~K}$ ultra-high definition, and in virtual reality, allowing the users to watch a 360-degree display or choose the viewing angle" (Jason, 2017). 
In the near future, the virtual reality will also lead to completely new experiences of watching sports competitions. NextVR's executive director, Brad Allen, graphically described how virtual reality will enhance the experience of attending a game. The viewer will watch the game at home together with a friend who is watching it in his home, and the virtual reality will make them feel like they were at the stadium. "We're talking to each other, and it's like we're on the field and watching the game," Allen said. "That's where this is going" (Jason, 2017).

By investing enormous resources in the virtual reality industry, the heads of Facebook, the largest social network, are also announcing a real virtual revolution that will enable their future users "to be wherever they want, with whomever they want, regardless of geographical boundaries" (Mitrović, 2016). These are the words of Technical Director of Palo Alto's giant, Michael Schroepfer, who announced the ambitious Facebook's plan to create a functional teleporting device by 2025 , based on the Oculus Rift virtual reality system.

According to the announcement, it would allow the "mental transportation" of individuals, so that people would have the feeling that they could go anywhere and do whatever they wanted regardless of where they were in the world. To create their own virtual 3D worlds, if necessary. Therefore, it is not difficult to predict what kind of marketing and sales potential we're talking about here (Mitrović, 2016).

\section{The Sports Industry and Sports Broadcasts in a} Symbiotic Relationship

Authors Cutlip, Center, and Broom, who work in communications and public relations, are in agreement that the Internet is "the most widespread exponent of the communication revolution," and that "advanced technology has changed the production, distribution, presentation and storing of information" (Cutlip et al., 2003).

In the sports industry, the fact is that live broadcasts have altogether changed the way fans experience sports, and they have also completely changed the entire sports business. Television networks and Internet companies from around the world "pay billions of dollars for the broadcasting rights for sports events, and sports organizations get valuable promotion, exposure in the media, and status through their broadcasts in electronic media"
(Masterlexis et al, 2005).

Also, it is indicated that the sports industry and business related to TV broadcasting rights for the games have an almost symbiotic relationship, which is further strengthened by a number of innovative ways to meet the needs of viewers who are not able to watch desired sports events live in the arena or at the stadium.

While sports organizations rely on broadcasters for revenue and publicity, the electronic media know that sports events are a sure way to attract viewers for which the companies that are being advertised will pay to address them (Masterlexis et al, 2005).

A particularly important aspect is that with the accelerated development of new digital media and social networks, the significance, impact, and value (media, financial, market, etc.) of athletes grow as well. One of the best soccer plays of the day, Cristiano Ronaldo, for example, is the leading star not only on the soccer field, but also on the social networks "field". The Portuguese player has 112 million followers on Instagram, 60 million followers on Twitter, and nearly 123 million followers on Facebook.

For example, the most popular Serbian athlete Novak Đoković is followed by 7.2 million people on Facebook, almost 8 million people on Twitter, and 3.5 million followers on Instagram.

\section{The New Media Intertwined Impact On Sports}

Unique for all online networks of this kind are tools and methods of visitor communication who share their own experiences, spend time with people who have the same interests, and find old friends and business partners. In any case, all these networks use similar methods to attract and retain visitors, and on the other hand contain different approaches to the integration of information and the interpretation of communication tools (Comer, 2001).

In addition, the impact of new media and social networks in contemporary civilization is becoming more pronounced, and in the modern sports industry information, marketing, sales, and even political impact can be distinguished. This was especially visible recently, when US athletes almost "went to war" with US President Donald Tramp because they kneeled, sat or held a raised fist during the US 
national anthem, thus protesting against the way the police treat African Americans, and against the increasingly pronounced discrimination and social injustice in the United States.

Numerous mainstream media did not show the "rebellious" acts of US athletes in detail, but the social networks immediately assumed the function of a "public broadcaster", and spread information about athletes who refused to stand at the flag raising event before the start of the match.

US President Donald Tramp even called on club owners to fire the players who did not standing calmly during the national anthem, and said that the National Football League (NFL) should introduce stringent rules to ban kneeling. On Twitter, his favorite online herald, among other things he wrote, "Facebook has always been anti-Trump. The Networks have always been anti-Trump"1.

The Internet and digital communication channels have also made possible the up until recently unseen marketing and sales potential, manifested in the increase in the profits of the entire sports industry. E-commerce has launched merchandizing, and product selection and related services management in sports (selling jerseys, equipment, tickets, etc.) into a dimension the income and profit margin of which is practically impossible to determine.

\section{Athlete and Fan Tweets}

Social networks have become an indispensable online tool for athletes, their clubs and/or sports organizations. Facebook, Twitter, and Instagram are the most popular digital communication channels for global sports stars to address the public and their fans. Equally, the fans gladly use these interactive online services to communicate with their sports "idols" on a large scale.

Nielsen, one of the leading companies in the United States that examines the media and the media market (Nielsen, founded in 1923 in Chicago), in line with the new digital trends in its diverse portfolio offers research into the use of social networks by sports fans.

One of the research studies of this influential agency has shown that in the past several years the influ1 https://twitter.com/realDonaldTrump/ status/913034591879024640 ence of Twitter has increased, especially among the audience watching sports events. It turned out that sports fans obviously like to share their impressions about the games with others online. For example, in 2013 as much as 50 percent of tweets about television in the US, a total of 492 million sent tweets, were related to sports events [Nilsen, 2014].

Nielsen's research also showed that 12 out of 20 of "the most tweeted" TV shows in the US that year were about sports events.

Keeping in mind that almost every sports event has a specific character, the so-called "hashtag" related to it, that allows the users to easily find messages about a specific sports (or another) topic or content, this allows for a new type of user engagement, creating a relationship with an audience that was not possible up until a few years ago.

\section{Conclusion}

The accelerated development of media and various forms of communication during the late $20^{\text {th }}$ and early $21^{\text {st }}$ century greatly contributed to the enormous popularity and development of sports, and consequently of the entire sports industry. Traditional electronic media - television and radio - as well as new digital media based on online platforms have completely changed not only the sports industry, but also the way in which it communicates with the targeted public.

Also, the contemporary sports industry spreads its global influence thanks to the media, for the most part, and at the same time the means of mass communication develop their significance, distribution, and influence on the public by covering these very sports and the whole of the accompanying industry.

Social networks, such as Facebook and Twitter, and advanced technologies, such as virtual and augmented reality, have also changed the way fans communicate with teams, players, sports people, and colleagues. The impact of new media on the sports industry will undoubtedly continue to evolve in the years to come.

\section{References}

Comer, D.E. (2001), Povezivanje mreža TCP/IP - principi protokoli i arhitekture, CET, Beograd, pp. 57

Craig, R. (2010), Onlajn novinarstvo, Clio, Beograd, pp. 24

Cutlip, M.S, Center, H.A and Broom, M.G. (2003), 
Odnosi s javnošću, MATE, Zagreb

DiMoro, A. (2015), The growing impact of social media on todays sports culture, available at: https://www. forbes.com/sites/anthonydimoro/2015/07/02/the-growing-impact-of-social-media-on-todays-sports-culture/\#49b7803331a2 (accessed 16 September 2017)

Jason, D. (2017), Learn how sports media is changing, available at: http://www.businessinsider.com/ignition-2017-learn-how-sports-media-is-changing-2017-5 (accessed 15 September 2017)

Kaplan, A. M., Haenlein, M, (2010), Users of the world, unite! The challenges and opportunities of Social Media, Business Horizons, Volume 53, Issue 1, January-February 2010, pp. 59-68

Masteralexis, L.P, Barr, A.C, Hums, M. (2005), Principles and Practice of Sport Management, Jones \& Bartlett Publishers, Berlington MA
Mitrović, U. (2016), Faustovska borba za dušu potrošača, Nacionalna poslovna revija, broj 8, Maj, pp.75

Nešić, M. (2007), Sport i menadžment, Tims, Novi Sad, pp. 235

Nilsen (2014), available at: /http://www.nielsen.com/us/ en/insights/news/2014/sports-fans-amplify-the-actionacross-screens.html

Šurbatović, J. (2014), Menadžment u sportu, Zavod za udžbenike, Beograd, pp. 286

\section{Corresponding author}

Uroš Mitrović, $\mathrm{PhD}$, assistant professor

Faculty of Sports, Union - Nikola Tesla University, Belgrade, Narodnih heroja 30/I

T: +381114044062

E: uros.mitrovic@fzs.edu.rs 